DOI: $10.13037 /$ ci.vol20n44.6061

\title{
O telejornal e seu (tele) espectador: um diálogo com Robert Stam sobre a natureza da TV hoje
}

THE TELEVISION NEWS AND ITS VIEWER: A DIALOGUE WITH ROBERT STAM ON THE NATURE OF TV NOWADAYS

\section{Vânia Maria Torres Costa ${ }^{2}$}

ORCID: http://orcid.org/0000-0002-0493-8763

(Universidade Federal do Pará, Programa de Pós-Graduação Comunicação, Cultura e Amazônia. Belém-PA, Brasil).

\section{Alda Cristina Silva da Costa ${ }^{3}$}

ORCID: https://orcid.org/0000-00028430-5703

(Universidade Federal do Pará, Programa de Pós-Graduação Comunicação, Cultura e Amazônia. Belém-PA, Brasil).

\section{Célia Regina Trindade Chagas Amorim ${ }^{4}$}

ORCID: http://orcid.org/0000-0002-1073-795X

(Universidade Federal do Pará, Programa de Pós-Graduação Comunicação, Cultura e Amazônia. Belém-PA, Brasil).

\footnotetext{
${ }^{1}$ Trabalho apresentado em primeira versão no $15^{\circ}$ Encontro Nacional de Pesquisadores em Jornalismo SBPJor (Associação Brasileira de Pesquisadores em Jornalismo) em São Paulo, na USP, em novembro de 2017, em mesa coordenada pela RENAMI - Rede de Pequisa Narrativas Midiáticas Contemporâneas, intitulada 'Narrativas, linguagens e novos formatos'.
} 
Palavras-chave: Jornalismo de TV. Rede Globo. Robert Stam. Abstract

\section{Resumo}

Refletimos sobre a televisão como mediadora da relação com o telespectador, considerando modos de encenação do jornalismo em relação à audiência. Dialogamos com Robert Stam no texto 'o telejornal e seu espectador', no qual infere o telejornal como agradável, em comparação com elementos fílmicos e televisivos. Analisamos a natureza da televisão e as inovações no telejornalismo no Brasil ao observar o que mudou na narrativa audiovisual. Selecionamos quatro edições de telejornais da Rede Globo, a partir das quais constatamos novas sociabilidades, mais improvisação e intimidade entre notícia e público.
We reflected about television as a mediator of the relationship with the viewer, considering ways of staging journalism in relation to the audience. We spoke to Robert Stam in the text 'the television news and its spectator', in which he infers television news as pleasant, in comparison to film and television elements. We analyze the nature of television and the innovations in telejournalism in Brazil by observing what has changed in the audiovisual narrative. We selected four editions of Rede Globo news programs, from which we found new sociabilities, more improvisation and intimacy between news and public.

Keywords: TV journalism. Rede Globo. Robert Stam.

\section{Considerações iniciais}

Cada vez que uma nova mídia surge na sociedade, a mídia 'tradicional' tem sua sobrevivência questionada. Foi assim com o livro, com o rádio, com o jornal e agora com a TV, que reinou soberana até o final do século passado. Hoje vem dividindo a atenção com as mídias digitais na Internet. Mesmo assim, ainda predomina como mídia mais acessada do Brasil, conforme pode ser constatado na 'Pesquisa Brasileira de Mídia 2016' (BRASIL, 2016)², na qual a televisão aparece como meio de comunicação dominante no território nacional. Nesse sentido, a televisão ainda pode ser considerada um dos "fenômenos culturais mais importantes de nosso tempo", conforme aponta Machado (2000, p. 15), assim como vem produzindo novos diálogos com o telespectador, principalmente com o avanço das tecnologias digitais³. Já nos diz Williams (2016) que uma das formas inovadoras da televisão é a própria televisão.

Apesar da pesquisa referenciada acima, observamos, principalmente a partir do 2 A 'Pesquisa Brasileira de Mídia 2016' foi elaborada pela Secretaria Especial de Comunicação Social da Presidência da República. Os dados foram coletados pelo Instituto IBOPE, em todo o território nacional, com pessoas de 16 anos ou mais idade. Foram realizadas 15.050 entrevistas domiciliares face a face, no período de 23 de março de 2016 a 11 de abril de 2016, em 740 municípios das 27 Unidades da Federação (BRASIL, 2016). A televisão desponta na frente com a preferência de $89 \%$ da população. A rede mundial de computadores desponta como segunda opção dos brasileiros na busca de informação (49\%); o rádio (30\%); os jornais $(12 \%)$ e as revistas $(1 \%)$.

${ }^{3}$ O presente artigo não tem o objetivo de contrapor ou discutir o fenômeno das mídias digitais na Internet, apenas tomá-las como um referencial de adequação da linguagem televisiva com o público. 
avanço da Internet e das tecnologias digitais, certo 'sombreamento' sobre o consumo da televisão 'tradicional' e de seus produtos. A TV vem, a cada dia, dividindo a soberania do poder da imagem em movimento, recurso que a diferenciou dos meios de comunicação anteriores, pois na atualidade a sociedade em rede agrega ao audiovisual a potencialidade de mais interação com o público.

Nesse ambiente de convergência, entre mídia tradicional e 'auto comunicação de massa' (sociedade em rede), conforme denominação do sociólogo Castells (2015), as redes horizontais de comunicação unidirecional, tais como TV, rádio e mídia impressa, estão cada vez mais misturadas, em um formato híbrido. As novas práticas de acesso aos conteúdos audiovisuais estão mudando o consumo linear da TV para um consumo de programas selecionados em uma 'segunda tela' (computador, tablet, smartphone).

Diante desse novo cenário, queremos entender como o jornalismo de TV vem reagindo a esses novos modos de relação com a audiência. Mais precisamente, nossas reflexões voltam-se ao telejornalismo atual como caminho para compreender o audiovisual televisivo, seus modos de produção, como entram em cena o texto, a imagem e o som quando se trata de noticiar o que de mais importante acontece a cada dia. O que nos move é discutir como a TV diz o que diz sobre o cotidiano na atualidade. Do mesmo modo, como a TV tem reconfigurado suas linguagens e conteúdos diante da onipresença das novas tecnologias e das exigências de um público que apela constantemente por mudanças e criatividades.

Assim, propomo-nos refletir sobre a televisão como mediadora da relação com o telespectador, a partir da utilização de recursos narrativos audiovisuais na produção de sentidos e na inclusão significativa do público na cena do telejornalismo. Para isso, dialogamos e reatualizamos o texto escrito por Robert Stam, em 1985, denominado 'O telejornal e seu espectador', considerando sua importante contribuição e atualidade, ao problematizar a construção narrativa televisiva e sua relação com o público.

Certamente a Internet nesse período ainda estava se configurando, e a TV não sofria nenhum impacto do novo meio que estava chegando. Mas, nesse texto, o autor identifica os modos como a televisão proporciona prazer ao telespectador, recorrendo às teorias do cinema. Nossas análises são centradas nessas construções teóricas de Stam sobre esse "aparelho de base televisual" como produtor de narrativas e no modo como essas narrativas dialogam com o telespectador.

As argumentações de Stam foram tomadas, por nós, como construtos metodológicos, assim como a concepção de narrativa desenvolvida em Ricoeur (1994), compreendendo 
as narrativas para além das representações, como estruturas que preenchem de sentido a experiência e instituem significação à vida humana. Ricoeur (1994, p. 85) propõe o processo de tessitura da narrativa em relação à estruturação de sentido do tempo. "O tempo torna-se tempo humano na medida em que é articulado de um modo narrativo, e a narrativa atinge o seu pleno significado quando se torna uma condição da existência temporal”.

Do mesmo modo, recorremos à compreensão de "narrativas televisuais", a partir de Marialva Barbosa. Para ela, a narrativa televisual é "o resultado de um processo de entrelaçamentos de múltiplas linguagens e gêneros midiáticos [...] que remetem ao exercício das artes de fazer produzido pelo público”. Tais processos mesclam práticas culturais nos modos de contar histórias, "ora dependente da convenção de veracidade, ora dependente da convenção de ficcionalidade" (BARBOSA, 2007, p. 16).

Com Stam observamos os elementos em cena: os cenários, os repórteres, os apresentadores, o estúdio, a externa, as imagens, o som, o texto. Buscamos resposta para entender, tal qual o autor, por que o noticiário ainda se mantém agradável hoje; o que teria mudado em três décadas; como se constitui a linguagem televisiva em diálogos com a audiência na contemporaneidade. Nossas reflexões têm como base empírica quatro edições de telejornais: Bom Dia Brasil, Jornal Hoje, Jornal Nacional, Jornal da Globo, todos da Rede Globo de Televisão, exibidos no dia 2 de janeiro de 2017. Portanto, nosso foco é a TV aberta e o telejornalismo de rede, aquele que é exibido simultaneamente em todo o território nacional.

\section{A televisão em diálogo com Robert Stam}

Robert Stam é um estudioso do cinema e do pensamento multicultural e multidisciplinar, com influência, entre outros, do pensamento de Mikhail Bakhtin e sua concepção dialógica, por entender que o 'aparelho de base' (televisão) tem tanta importância quanto o público: "não apenas sua base instrumental, composta de câmera, projetor e tela, mas também o espectador, enquanto sujeito que deseja e do qual a instituição do cinema depende, pois é seu objeto e seu cúmplice” (STAM, 1985, p. 75).

No texto 'O telejornal e seu espectador', Stam infere o telejornal como agradável, pela possibilidade da utilização de elementos que incluem e aproximam o telespectador. O autor examina determinados procedimentos utilizados tanto pelo telejornal como pelo filme de ficção, estabelecendo aproximações e diferenças entre as duas narrativas, a partir 
de alguns teóricos do cinema, para compreender a condição do espectador na relação com a mídia televisiva. Para ele, o noticiário da televisão é o herdeiro de duas lógicas discursivas distintas e, em alguns sentidos, contraditórias: a fílmica e a jornalística.

Diferente do cinema, o 'aparelho de base televisual' oferece prazeres ainda mais variados e multiformes, pois o espectador tem sua percepção estendida, proporcionando, segundo Stam, uma sensação embriagante de poder visual, sendo "todo preceptor", dilatado até o limite no puro ato de olhar. A qualidade 'vivida' da televisão proporcionaria diversas outras gratificações, entre elas, um suspense real, por oposição ao fabricado pelo cinema.

Entre tevê e cinema, Stam destaca as "identificações primárias" e "identificações secundárias", referenciadas nos estudiosos do cinema. Nas primeiras, encontra-se o ato de percepção, que cria uma ubiquidade ilusória, isto é, do sujeito que tudo vê a partir do que a mídia televisiva mostra. $\mathrm{O}$ espectador se identifica com o ato de olhar a si mesmo como puro ato de percepção. Para Stam, a televisão permite que participemos do tempo literal das pessoas que estão em outros lugares, proporcionando não apenas o dom da ubiquidade, mas a ubiquidade instantânea.

A "identificação primária" do espectador não seria com os acontecimentos ou personagens descritos na tela, "mas antes com o ato de percepção que torna possíveis as identificações secundárias, um ato que é ao mesmo tempo canalizado e construído pelo olhar prévio da câmera e pelo projetor" (STAM, 1985, p. 75). As "identificações secundárias" podem ser entendidas como os outros elementos que são construídos ou projetados a partir do ato de percepção, isto é, a identificação com o olhar dos personagens ou com os outros aspectos pertencentes à construção narrativa ou jornalística.

\section{O jornalismo de TV como produção audiovisual}

Comecemos então por descrever a estrutura de um telejornal, pensando cada edição como uma narrativa, na qual identificamos uma longa sequência (início, meio e fim) formada por vários pequenos materiais, sejam eles gravados ou ao vivo. Os conteúdos são ordenados em blocos e separados pelo intervalo comercial. Então temos uma narrativa diferente do cinema. Há uma linearidade que é 'quebrada' por pausas, para a entrada de outros assuntos. Portanto, observamos que cada bloco, se constitui em uma pequena narrativa dentro da grande narrativa, de acordo com a hierarquia proposta pela produção jornalística. 
Stam (1985, p. 80) observa o telejornal a partir de uma natureza ficcional, "como uma montagem cujos procedimentos são semelhantes aos da ficção", pois as histórias apresentadas no noticiário, "enquanto elemento constitutivo da vida humana, são agradáveis porque trazem o consolo da forma ao fluxo da experiência humana", gerando assim o prazer da ficção. Essa atração exercida sobre o público se assemelha, segundo o autor, aos trabalhos desenvolvidos por Enzensberger, Dyer e Jameson, que observam para além do "efeito ideológico que manipula as pessoas de maneira a que se sintam cúmplices das relações sociais em vigor".

Um programa de notícias típico, observa Stam (1985, p. 81), apresenta macroficções, unidades sintagmáticas mais amplas e microficções, como as pequenas piadas que encerram o noticiário do dia. O telejornal se configuraria, para ele, como uma prática "significante com procedimentos ordenadores identificáveis, um discurso organizado, mais do que fatias não mediadas de vida”. O telespectador se vê obrigado a seguir uma sequência pré-determinada em moldes narrativos previsíveis, fornecidos pelo intertexto televisual e cinematográfico. Há um tempo de exibição, ao vivo ${ }^{4}$, no qual os materiais são anunciados por seus apresentadores, em linguagem clara e coloquial. $\mathrm{O}$ jornalismo de TV deve ser ofertado como se fora ao vivo, atestando a atualidade como caminho para presentificar as notícias produzidas. O que diferencia a TV dos outros meios de comunicação é que a equipe de reportagem precisa ir ao local dos acontecimentos, para captar as imagens, mostrar a vida em movimento, fazer ver.

Stam (1985, p. 76-77) relaciona cinema e televisão como aparelhos de simulação que não apenas representam o real, "mas que também estimulam intensos efeitos nos sujeitos". Ele destaca dois aspectos sensoriais importantes que a televisão provoca: o prazer de olhar e o prazer de ouvir, permitindo assim "ver sem sermos vistos e ouvir sem sermos ouvidos". A situação do 'sujeito que tudo vê' e a sensação de ubiquidade instantânea devem atravessar toda a narrativa, fazendo crer que se vê melhor do que se o telespectador estivesse na própria cena. "Essa impressão construída de absoluta imediatez, constitui uma das inegáveis satisfações que o noticiário nos proporciona" (STAM, 1985, p. 76). Ou então, aquilo que nos indica Fechine (2008, p. 83), "o espectador não apenas vivencia um determinado acontecimento (toma parte) através da transmissão direta, mas vive a própria transmissão direta como um acontecimento (do qual toma parte)".

${ }^{4}$ Hoje o telespectador já pode baixar o telejornal a partir de ferramentas específicas no ambiente de rede, 'burlando' a instantaneidade histórica da televisão. Um exemplo desse acesso foi a possibilidade de captura dos quatro telejornais tomados nesta análise, observados a partir do aplicativo Globoplay, disponibilizado pela Rede Globo. É uma plataforma de vídeos da emissora, lançada em novembro de 2015. 
Do mesmo modo, nas 'identificações secundárias', os sujeitos, ao assistirem um telejornal, encontram a possibilidade de se identificar com os vários personagens que se apresentam na construção da narrativa jornalística, como apresentadores, correspondentes, políticos e celebridades, personagens dos comerciais e as 'pessoas comuns' retratadas no noticiário. Os apresentadores, segundo Stam (1985, p. 78), representam, assim, o topo da hierarquia da identificação, ou seja, figuras simbólicas que indicam as trilhas a serem seguidas em "um mar tempestuoso de significações".

\section{Os telejornais e suas estratégias narrativas}

Ao analisar as estratégias narrativas do jornalismo de TV na atualidade, temos que entender um pouco do contexto da sociedade em rede, considerando que as chamadas mídias 'tradicionais' foram impulsionadas a repensar seu papel e seus produtos nesse ambiente da internet e das tecnologias digitais. Mesmo considerando as transformações operadas nos últimos vinte anos, a televisão, afirma Castells (2015, p. 112), "continua a ser um veículo de massa importante, mas seu fornecimento e seu formato estão sendo transformados à medida que a recepção se individualiza", seja na mudança de comportamento do consumo dos produtos, que podem ser em plataformas distintas, seja nas transformações operadas pela tecnologia.

O redesenho do cenário da comunicação vem individualizando a recepção da programação televisiva, pois o veículo continua a ser meio de comunicação de massa da perspectiva do emissor, mas de acordo com o sociólogo, observa-se cada vez mais a "capacidade de controlar a recepção da televisão com a inclusão de softwares capazes de programar gravações e pular anúncios" (CASTELLS, 2015, p. 107).

É nesta perspectiva, que empreendemos nossas análises dos telejornais, pois constatamos mudanças no modo do 'aparelho de base televisual' narrar as histórias ou experiências cotidianas para a audiência. Comecemos a pensar o telejornal em um nível de maior detalhamento, observando suas pequenas narrativas (matérias e entradas ao vivo) dentro da grande narrativa. A organização do discurso midiático, aponta Motta (2013), não é aleatória, mas combina contextos pragmáticos e políticos e produz certos efeitos.

Assim, temos na escalada - a abertura do telejornal - uma oferta do cardápio de cada edição. $\mathrm{Na}$ abertura das edições, temos o apresentador em cena, intercalado pelas imagens externas, em uma conjugação de texto de estúdio com as cenas da rua. Por isso, 
é o momento de trazer uma boa dose de prazer. Nas edições analisadas, as escaladas começam por assuntos mais pesados (hard news) e terminam com assuntos mais leves (soft news), tal qual a ordem dos telejornais. Todos os apresentadores observados na coleta empírica deste trabalho abrem a escalada com tom sério, pesado e terminam com um leve sorriso nos lábios. Marialva Barbosa (2007) denominará esse 'cardápio' de lógica da narrativa da televisão, que se organiza em articulações temáticas, colocando em evidência o cotidiano das maiorias e apelando às sensações do público. As narrativas serão aproximadas por regimes de identificação.

Os apresentadores cumprimentam o telespectador, passam a anunciar as manchetes do dia. Intercalam o que consideram os assuntos mais importantes com imagens, texto verbal e som. Essa voz narrativa constitui, em Ricoeur (1994), aquele que se dirige ao leitor (ouvinte ou espectador) apresentando-lhe o mundo. O que entra ali na abertura já nos provoca reflexões interessantes. O que é mais importante? A notícia e seu conteúdo ou a imagem que chama a atenção e convoca o telespectador no ato da percepção?

Cremos, pelas análises, que temos as duas possibilidades em cena. Há os assuntos considerados importantes por suas repercussões no cenário nacional, e há aqueles materiais que só se sustentam graças à existência das imagens e ao inusitado do fato. Como exemplo desta última situação, citamos o Jornal Hoje de dois de janeiro de 2017, ao anunciar a queda de um raio que atinge uma mulher em uma praia de São Paulo. As imagens são de um cinegrafista amador. O detalhe do raio atingindo a mulher é marcado por um círculo, no momento da exibição.

Sabemos que tal fato jamais ganharia destaque se não houvesse as imagens excepcionais e extraordinárias, já que a vítima é uma desconhecida, tanto que no texto se diz "uma mulher". E o extraordinário, como diz Bourdieu (1997, p. 26), "rompe com o ordinário, pelo que não é cotidiano [...] extra cotidiano". Tal cena, como aponta Bourdieu, não é prevista pela ótica ordinária, o que por si só impulsiona a audiência, ativa a recepção e permite essa 'presentificação' televisiva, quase como se estivéssemos lá.

Constatamos, também, mudanças interessantes de acordo com o horário de exibição de cada um dos telejornais (Bom Dia Brasil, Jornal Hoje, Jornal Nacional e Jornal da Globo). Todos se organizam estrategicamente, de modo a envolver o telespectador, de maneiras diferentes. Começando pelas cores e a composição do estúdio, que dialogam ora com o mundo lá fora ora com o mundo do próprio telejornal, pois é possível perceber, em alguns deles, além do estúdio, a redação da TV. Do amarelado leve da manhã (Bom Dia Brasil), à claridade do dia (Jornal Hoje), aos tons noturnos dos jornais da noite (Jornal Nacional e Jornal da Globo). Essa harmonia com a vida para além do estúdio também está 
associada ao ritmo da locução dos apresentadores.

No Bom dia Brasil, exibido de manhã cedo, quando o telespectador supostamente está acordando, o ritmo da locução é mais lento e das imagens também, os textos são mais longos e coloquiais. O texto é mais sonoro e, dentre os demais observados, é o único que informa a 'hora certa' a cada bloco. Assim, constatamos uma demarcação de tempo relevante para os telespectadores, entre ser informado e não perder a hora do trabalho.

No Jornal Hoje, no 'horário de almoço', o ritmo é mais rápido e agitado: textos curtos, mais informalidade, edição acelerada, assim como uma movimentação intensa na redação/estúdio. No Jornal Nacional, exibido no horário nobre da noite, o ritmo apresenta algumas semelhanças com o Jornal Hoje. No entanto, observamos algumas diferenças: maior formalidade no texto; pouco improviso e pouca movimentação de pessoas na redação/estúdio, que fica exposta ao telespectador.

O Jornal da Globo já é bem mais visual, como a se adequar ao horário do início da madrugada e tem um caráter de resenha do dia. Quase toda a escalada é atravessada por pequeníssimos trechos de imagens e sons dos VTs (matérias), que são os teasers, enquanto o apresentador narra em off. A locução é mais lenta, tendendo para o improviso, como a respeitar e entrar em sintonia com os horários em que o telespectador já está sonolento, após um longo dia de trabalho.

Os cenários são compostos de modo a ratificar o que diz Stam sobre o papel narcisista do telejornal, com sua capacidade de 'cobrir o mundo'. Por trás dos apresentadores aparecem mapas do Brasil, televisores que propõem o sentido da conexão com o 'mundo todo' e com o telejornal, prontidão dos jornalistas em acompanhar os fatos do dia. Portanto, temos o cenário ao vivo da redação como espaço vital dos departamentos de jornalismo, onde os jornalistas circulam, aparentemente, com a naturalidade do mundo real, enquanto apuram e produzem suas notícias, o que propõe o sentido de humanização nas rotinas de produção da emissora de TV.

Os blocos dos telejornais são encadeados pelo (s) apresentador (es) que abre(m) e fecha(m) cada um deles, como mediadores dessas narrativas. É um modo de manter a identidade do telejornal. Trata-se da serialidade, que de acordo com Machado (2000,p.84), é a "apresentação descontínua e fragmentada do sintagma televisual". Robert Stam (1985) reflete sobre o papel dos apresentadores-âncora como elos de identificação (BARBOSA, 2007) entre espectadores e noticiário. São sempre os mesmos apresentadores ${ }^{5}$, o mesmo cenário no estúdio e os mesmos comentaristas. Apenas em coberturas especiais é que

\footnotetext{
${ }^{5}$ Apenas nas edições de sábado os apresentadores são substituídos por plantonistas.
} 
podemos ver alguma alteração nessa estrutura.

Na década de 1980, Stam observa que os apresentadores se tornam personagens de construções engenhosas, com desempenhos diferenciados de acordo com os fatos que vão divulgar. Mudam o tom de voz, usam a ironia, o sarcasmo, expressões faciais e verbais, desabafos, lamentos, indignações, repreensões, conforme a mudança de assuntos. Nessa orquestração da construção telejornalística, diferente da atuação dos personagens no cinema, escreve Stam, os apresentadores ou outros profissionais envolvidos simulam uma não atuação premeditada que implica, simultaneamente, na presença e na negação das emoções e reações humanas normais.

Hoje, temos outra realidade. Entre os apresentadores cria-se o clima do bate-papo informal, algo mais recente nos telejornais. O apresentador propõe um desvelamento de si: diz que está gripado, que tem medo, faz piada e se humaniza. Ou, como diz Fechine (2008, p. 72): “quanto mais a TV demonstrar, através da incorporação de erros e acasos à transmissão, que não detém o controle sobre o que está sendo levado ao ar, maior a promessa de autenticidade associada, ideologicamente, ao direto". As matérias são comentadas aparentando improviso, como em uma conversa cotidiana entre conhecidos.

O estúdio é proposto como esse lugar da conversa principal, o correspondente a uma sala de estar. Os apresentadores são posicionados em uma cena de trabalho: o computador ou tablet e alguns materiais pessoais em cima da mesa. As roupas são elegantes e formais. Poucos acessórios, o cabelo é discreto e as cores também. A luz do estúdio é tão perfeita que não há sombras ao fundo, ao lado ou abaixo do pescoço dos apresentadores. Todo o telejornal produz o sentido de uma conversa informal com a audiência.

O texto verbal é lido pelo apresentador no momento de chamar as matérias ou as entradas ao vivo. A tela de leitura - o teleprompter - é posicionada entre a câmera e o apresentador. Todos esses equipamentos são ocultados, e utilizados para fazer crer que o texto é uma fala improvisada. E tal qual numa conversa entre amigos, não há script pronto. Sobre esse caráter de comunicação espontânea, Stam (1985, p. 78) aponta que a aparente fluência do texto "provoca respeito, enquanto os acessórios da espontaneidade geram um sentimento de comunicação não mediada".

Se no passado Stam aponta que a superioridade do apresentador está estruturada no próprio noticiário, hoje percebemos uma relativa mudança nessa relação. Os apresentadores ainda são os comandantes da exibição, mas dividem a importância dos fatos com os jornalistas envolvidos no telejornal e com os comentaristas, conforme observamos, por exemplo, no encerramento do Bom Dia Brasil, em que todos os apresentadores daquele 
dia aparecem virtualmente no estúdio. Tal estratégia possibilita legitimar o telejornal, produzido a partir de diversos correspondentes e colaboradores espalhados pelo Brasil e pelo mundo, ou seja, hoje, o trabalho é coletivo, é feito por muitos.

Em todos os momentos o telespectador parece, simbolicamente, estar presente. Nas entrevistas de rua ou no estúdio é como se ele estivesse ali. Levemente de lado estão entrevistador e entrevistados, que, com frequência, viram-se para a câmera como a incluir as perguntas e dúvidas do telespectador. O enquadramento está proposto em todos os manuais de TV: o repórter bem ao lado do cinegrafista - o mais próximo possível - para que o entrevistado, ao olhar para o repórter, com quem dialoga, pareça estar olhando para a câmera.

Os personagens convocados como exemplos da veracidade dos casos apresentados precisam estar na cena, exatamente nos locais onde é possível atestar os acontecimentos propostos pela narrativa. A imagem deles e seus depoimentos costuram a intriga da narrativa (RICOEUR, 1994). Toda a produção sintética da imaginação só aconteceria, diz Ricoeur, por meio das implicações do que ele chama de tradicionalismo ou mundo cultural, em que há uma conexão entre o trabalho criador do texto e o mundo social. $\mathrm{Na}$ narrativa jornalística há sempre uma relação íntima entre personagens e pessoas físicas porque personagens representam pessoas reais (MOTTA, 2013).

Nos telejornais, percebemos que mesmo quando os entrevistados não podem aparecer, por questões pessoais ou de segurança, os recursos de edição são utilizados para manter o entrevistado na cena e ainda com sentidos de suspense: penumbra, contraluz, escuro, voz alterada, texto em caracteres para explicitar a locução alterada com efeitos. Os personagens atestam a veracidade da construção narrativa, que os têm como exemplos no desenrolar da ação da intriga (RICOEUR, 1994). O desvendamento da história por etapas, os enigmas que fazem parte dela e a construção de um clímax sugerem a revelação da narrativa. Stam (1985) vai chamar os detalhes estratégicos destinados a produzir uma sensação de verossimilhança, "de efeitos de realidade". E nos argumentos de Bourdieu, (1997, p.28), o efeito de real implica produzir no telespectador, "o fazer ver e o fazer crer no que faz ver".

Como os personagens, os especialistas também são 'atores' fundamentais na construção da intriga. São os autorizados a explicar, esclarecer, orientar e também precisam estar na narrativa audiovisual. O cenário onde aparecem ratifica o peso de suas experiências e legitima o discurso narrativo. A professora universitária fala imersa em uma biblioteca, em edição do Bom Dia Brasil de dois de janeiro de 2017, explicitando aquilo 
que Motta (2013) chama de "plano de fundo" ou os "imaginários culturais”, representados nesta cena pelos livros impressos, que figuram como a produção de conhecimento de uma sociedade. Os caracteres que a identificam confirmam sua função e importância social como especialista apta a opinar.

Para atestar a veracidade da cena, os repórteres e cinegrafistas 'vivenciam' situações 'reais', agindo ao mesmo tempo, como testemunhas e autores das matérias aptos a encenar o lugar do telespectador. No Jornal Hoje, de 02 de janeiro de 2017, o repórter Tonico Ferreira aparece empurrando um carrinho de supermercado, no qual coloca os produtos da cesta básica. E o texto confirma: "colocamos no carrinho alguns itens da cesta básica que se pode comprar com esse valor". Trata-se de uma imagem que aproxima o telespectador não só para o mundo do cotidiano do consumidor, como também para o telejornal, que fala para e com o telespectador sobre a rotina cotidiana.

Em outros momentos, podemos perceber a presença mais ativa do telespectador no texto verbal e na locução. Temos um exemplo do Jornal da Globo, de dois de janeiro de 2017, em um VT sobre a bolsa de valores, no qual o repórter Tiago Eltz diz, posicionado de frente para a câmera: "e depois de um ano tão trágico, com números tão ruins para a economia brasileira, você se depara com esse índice, digamos, substancioso do Ibovespa e pode ser que você comece a pensar: bom, vou pegar meu dinheirinho e aplicar na bolsa. Mas calma, que os analistas alertam que pode ser que você chegue meio atrasado na festa" (GLOBO, 2017, grifo nosso). O repórter supõe as reações da audiência, imagina o que pensa e propõe soluções, oferece ajuda, vai buscar 'socorro' com alguém que entenda do assunto - o especialista.

As entradas ao vivo inserem o telespectador nos acontecimentos do dia ou da noite, o que foi facilitado pelos avanços tecnológicos: os equipamentos estão muito mais leves, as captações de sinais foram simplificadas e as equipes reduzidas. E tudo tende a parecer ao vivo no telejornal, mesmo quando não é. "No noticiário, a parte da transmissão direta - a informação transmitida pelo apresentador, diálogos, eventuais eventos importantes ao vivo- 'contamina' metonicamente a totalidade das notícias” (STAM, 1985, p. 75, grifo do autor). Essa sensação ilusória de atualidade ou impressão construída de absoluta imediatez, conforme escreve o autor, residiria numa das inegáveis satisfações que o noticiário proporciona ao público.

Essa oferta de atualidade ganhou um novo ritmo no jornalismo de TV com as redes sociais na internet, pois o telejornal também deve dialogar com a audiência, via sociedade em rede, uma vez que os novos dispositivos, como notebooks e tablets, passam a compor 
o cenário do estúdio, como instrumento de trabalho dos apresentadores, que acompanham ao vivo o mundo lá fora. $\mathrm{O}$ telejornal se atualiza para fazer frente à queda nos índices de audiência. Passa a acompanhar a dinamicidade das transformações e do comportamento do público.

Com relação ao texto dos repórteres, a informalidade também toma a frente. Em um VT do Jornal Hoje, a repórter diz: "a unidade de pronto atendimento em Umuarama Araçatuba tá pronta desde 2014" (GLOBO, 2017b). O 'tá' tem a proposta de aproximar a linguagem verbal da fala comum, substituindo o 'está' por seu uso reduzido e informal, muito frequente, já que a linguagem da internet tende a tudo sintetizar, abreviar.

O texto verbal também aparece em caracteres na tela em várias situações para explicitar informações estatísticas ou termos pouco usuais ao telespectador, seja na gravação externa ou no estúdio. Essas produções de sentido vêm reforçar em imagens grafadas o que o texto verbal e a locução estão dizendo. Assim como os textos são grafados na tela, explicitando o poder das imagens, o som também tem um papel relevante nos usos da linguagem audiovisual. Aparece na voz dos jornalistas, ao longo dos textos narrados ou nos chamados 'sobe som', quando entra em cena o som ambiente: o som da rua, uma gargalhada, um grito, uma explosão, um tiroteio. Ao longo de todas as reportagens editadas (VTs), o som aparece como BG - background (som de fundo), para dar o tom de realidade à narrativa.

A previsão do tempo já não é mais estática como antes, quando se limitava ao mundo físico, à natureza sem homem. Ela teve que se reinventar. "Nas primeiras exibições do Jornal Nacional, usava-se o adjetivo na previsão do tempo. Mas isso foi proibido, porque se falava assim: 'o tempo é bom no Nordeste'. Escreveram para a redação: 'o tempo é bom para quem? Para carioca ir à praia? Para mim, que estou na lavoura, é ruim'. Tivemos que mudar. Então, o adjetivo caiu" (MEMÓRIA GLOBO, 2/2/2009 apud BONNER, 2009).

Os quadros de previsão do tempo se tornaram fixos em todos os telejornais. Hoje, eles mostram as implicações da natureza na vida do homem. Apresentam fatos relacionados às diferenças climáticas de cada região. As narrativas trazem informações sobre enchentes, tempestades, secas e atoleiros, entre outros. O tempo é humanizado e animado com uso de telões explicativos, o que Stam chama de "geografia criativa". A queda do raio que fez uma vítima é imediatamente conectada com a previsão do tempo, momento em que a jornalista abre seu comentário ensinando 'como se proteger dos raios'.

Por meio do poder da tecnologia, apresentador e comentaristas dialogam em espaços diferentes. No Jornal Nacional do dia dois de janeiro de 2017, a apresentadora 
conversa com a jornalista da previsão do tempo, que está em outro lugar e outro cenário. As duas aparecem de corpo inteiro. O enquadramento simula uma conversa direta e a apresentadora já não esconde mais o equipamento preso na cintura, ligado ao microfone de lapela, o que antes era inconcebível.

\section{Considerações finais}

Ao referenciarmos Stam na construção deste artigo, ousamos fazer uma releitura de suas reflexões para problematizar as propriedades narrativas da televisão na atualidade. Partimos do fato de que a TV continua dominante entre as mídias mais acessadas pelos brasileiros. A imagem, vista como real, como mundo em ação, é proposta como convite a experiências e vivências que propõem ao telespectador ver sem ser visto, com níveis cada vez maiores de detalhamento e de atualidade. O exercício do ver produz o sentido de ‘verdade' e 'realidade' nessa 'nova' TV que se oferta atenta aos diálogos, comentários e 'viralizações' que o ambiente virtual produz ao largo do alcance da emissora.

O telejornalismo, ontem e hoje, continua a utilizar "sem qualquer sacrifício de probidade ou responsabilidade" (FRANK, 1974 apud STAM, 1985, p. 80) os atributos da ficção, contando com um começo, um meio e um fim, essenciais ao drama, e inerentes à narrativa televisual. $\mathrm{O}$ noticiário continua sendo uma ficção, partindo da concepção stamiana, uma vez que simula a representação de intrigas de modo a envolver a audiência pelas propriedades audiovisuais. Apresenta-se intimista e imita os ritmos característicos do diálogo, produzindo histórias, organizando o tempo e convocando o telespectador como coparticipante do telejornal.

A narrativa televisual ganha novos contornos de aproximação ao falar com o telespectador. Ela aparenta invisibilizar o dispositivo mediador da relação, para aproximar jornalistas e público, buscando o texto coloquial, o falar direto com a câmera/telespectador, o improviso, a espontaneidade. Assim, os seres da televisão tornam-se humanos, podendo se emocionar ou errar, tal qual na vida real. Eles agora circulam de corpo inteiro e já não se escondem atrás das bancadas, mostram-se, porque se não o fizerem, as redes sociais o farão. As regras do jogo mudaram. É preciso mostrar 'tudo', tornar visível, simular o real, caso contrário corre-se o risco de que a narrativa seja descontruída em seu poder de ordenar o mundo.

Evidenciamos que este artigo é uma tentativa cartográfica e comunicativa em construção, entendida como levantamento do status quo vivido pela televisão aberta, 
produção, conteúdo e linguagens de seus produtos, com o objetivo de interpretar o papel e o caráter da televisão na contemporaneidade. São apontamentos de um projeto maior que visa entender como a televisão e seu telejornalismo têm enfrentado às transformações tecnológicas, sociais e culturais e as mudanças no modo de produzir, ver, ouvir e assistir tevê.

\section{Referências}

BARBOSA, Marialva. Televisão, narrativa e restos do passado. E-compós, Brasília, v. 8, p. 2-21, abr. 2007. Disponível em: <http:/www.compos.org.br/seer/index.php/e-compos/article/ view/138/139>. Acesso em: 20 jan. 2017.

BONNER, William. Jornal Nacional: modo de fazer. São Paulo: Globo, 2009.

BOURDIEU, Pierre. Sobre a televisão. Rio de Janeiro: Jorge Zahar, 1997.

BRASIL. Pesquisa brasileira de mídia 2016: hábitos de consumo de mídia pela população brasileira. Brasília: Secom, 2017.

CASTELLS, Manuel. O poder da comunicação. São Paulo/Rio de Janeiro: Paz e Terra, 2015.

FECHINE, Yvana. Televisão e presença: uma abordagem semiótica da transmissão direta. São Paulo: Estação das Letras e Cores, 2008.

GLOBO. Jornalismo. Globo Play. [S.1.]: Globo Comunicação e Participações S. A., [201-]. Disponível em: https://globoplay.globo.com/programas/jornalismo. Acesso em: 00 jan. 2017.

GLOBO. Bom Dia Brasil - Edição de segunda-feira, 02/01/2017. Globo Play. [S.1.]: Globo Comunicação e Participações S. A., 2017a. Disponível em: https://globoplay.globo. com/v/5549456/. Acesso em: 02 jan. 2017.

GLOBO. JornalHoje-Ediçãode segunda-feira, 02/01/2017. Globo Play.[S.1.]: GloboComunicação e Participações S. A., 2017b. Disponível em: https://globoplay.globo.com/v/5550376. Acesso em: 04 fev. 2017.

GLOBO. Jornal Nacional - Edição de segunda-feira, 02/01/2017. Globo Play. [S.1.]: Globo Comunicação e Participações S. A., 2017c. Disponível em: https://globoplay.globo. 
com/v/5551421. Acesso em: 08 jan. 2017.

GLOBO. Jornal da Globo - Edição de segunda-feira, 02/01/2017. Globo Play. [S.1.]: Globo Comunicação e Participações S. A., 2017d. Disponível em: https://globoplay.globo. com/v/5551547. Acesso em: 08 jan. 2017.

MACHADO, Arlindo. A televisão levada a sério. São Paulo. Editora Senac, 2000.

RICOEUR, Paul. Tempo e narrativa. v. 1. Campinas: Papirus, 1994.

SODRÉ, Muniz. O monopólio da fala: função e linguagem da televisão no Brasil. 5. ed. Petrópolis: Vozes, 1984.

STAM, Robert. Introdução à teoria do cinema. Campinas: Papirus, 2003.

STAM, Robert. O telejornal e seu espectador. Novos Estudos CEBRAP, São Paulo. n. 13, p. 74-87, out. 1985.

WILLIAMS, Raymond. Televisão: tecnologia e forma cultural; tradução Márcio Serelle; Mário F. I. Viggiano. São Paulo: Boitempo; Belo Horizonte, MG: PUCMinas, 2016.

${ }^{2}$ Doutora em Comunicação pela Universidade Federal Fluminense (UFF), Mestre em Planejamento do Desenvolvimento pelo Núcleo de Altos Estudos Amazônicos (NAEA) - Universidade Federal do Pará (UFPA). Professora do Programa de PósGraduação Comunicação, Cultura e Amazônia (PPGCom/UFPA) e da Faculdade de Comunicação (Facom/UFPA) da Universidade Federal do Pará. Coordena o projeto 'Estrada de Ferro Belém-Bragança: sujeitos, memórias e interações comunicacionais na Amazônia paraense'. É uma das coordenadoras do Grupo de pesquisa Narramazônia Narrativas Contemporâneas na Amazônia Paraense - parceria entre UNAMA (PPGCLC) E UFPA (PPGCOM). Belém- PA, Brasil. E-mail: vaniatorrescosta@gmail.com.

${ }^{3}$ Pós-doutora pela Universidade da Amazônia; Doutora e Mestre em Ciências Sociais pela Universidade Federal do Pará. Professora do Programa de Pós-Graduação Comunicação, Cultura e Amazônia (PPGCom/UFPA) e da Faculdade de Comunicação (Facom/UFPA) da Universidade Federal do Pará. Coordenadora do projeto de pesquisa 
Mídia e Violência: percepções e representações na Amazônia, em parceria entre UFPA e Conselho Nacional de Desenvolvimento Científico e Tecnológico (CNPq) e do grupo de pesquisa e estudos Narrativas Contemporâneas na Amazônia - Narramazônia (PPGCOM/ CNPq/UFPA/PPGCLC/UNAMA).Belém -PA, Brasil. E-mail: aldacristinacosta@gmail.com.

${ }^{4}$ Pesquisadora em Pós-doutoramento no Centro de Estudos Sociais, Laboratório Associado, Universidade de Coimbra, Portugal. Núcleo: Democracia, Cidadania e Direito. Doutora e Mestre em Comunicação e Semiótica pela Pontifícia Universidade Católica de São Paulo (PUC-SP). Professora do Programa de Pós-Graduação Comunicação, Cultura e Amazônia (PPGCOM) e da Faculdade de Comunicação (Facom) da Universidade Federal do Pará - UFPA, Brasil. Coordenadora do Grupo e Projetos de Pesquisa Mídias Alternativas na Amazônia - UFPA e Cidadania Comunicativa: Desafios, lutas e direitos compartilhados na Amazônia (UFPa-CES/UC). Belém -PA, Brasil. E-mail: celia.trindade. amorim@gmail.com. 